\title{
Impact of education workshop on improving pharmacy students' knowledge about Helicobacter pylori infection: A randomized controlled study
}

\author{
Anas Alshkweiki ${ }^{1}$, Feras Elhajji ${ }^{2}$, Rana Abu Farha², and Raja'a Alqudah ${ }^{2}$ \\ ${ }^{1}$ Applied Science Private University Faculty of Pharmacy \\ ${ }^{2}$ Applied Science Private University
}

October 13, 2020

\begin{abstract}
Rationale, aims, and objective: Evidences show that the level of awareness about H.pylori is still low, and working on this issue is expected to be very impactful to improve infection rates and disease spread. This research aimed is to assess the level of knowledge and the degree of awareness among undergraduate pharmacy students in regard to $\mathrm{H}$ pylori diagnosis and management before and after delivering an educational pharmacy intervention. Methods: This is a randomized controlled study that was conducted in May 2020. During the study period, 72 pharmacy students were invited to attend a workshop about $\mathrm{H}$ pylori management and diagnosis. Participants' knowledge and general awareness about $\mathrm{H}$ pylori infection was evaluated before and after the workshop (25-minute educational lecture for the intervention group and educational pamphlet for the control group). At the end of the workshop participants' ability to distinguish and correctly diagnose virtual cases was tested. Results: Most of the participating students $(n=58,80.6 \%)$ haven't been involved in similar workshops previously. Following education workshop, students in the intervention group showed a significant improvement in their knowledge score (from 9.2 $(\mathrm{SD}=1.9)$ pre-workshop to $10.4(\mathrm{SD}=1.9)$ post-workshop, (P-value $=0.001)$ while students in the control group didn't (preworkshop knowledge score of $9.1(\mathrm{SD}=2.2)$ and post-workshop score of $9.4(\mathrm{SD}=1.6)$, ( $\mathrm{P}$-value $=0.324)$. Also, students in the intervention group produced better results than the control group in distinguishing and diagnosing provided $H$ pylori cases in the workshop with higher score of 2.2 for the intervention group compared to 1.6 for the control group $(\mathrm{P}$-value=0.026). Conclusion: Education workshops about $\mathrm{H}$ pylori infection are needed to build a strong base of qualified healthcare providers as an outstanding output of our higher educational programs, which in turn improves the quality and reduces the burden on healthcare systems.
\end{abstract}

\section{Hosted file}

H-pylori manuscript final.pdf available at https://authorea.com/users/366776/articles/ 486415-impact-of-education-workshop-on-improving-pharmacy-students-knowledge-abouthelicobacter-pylori-infection-a-randomized-controlled-study 

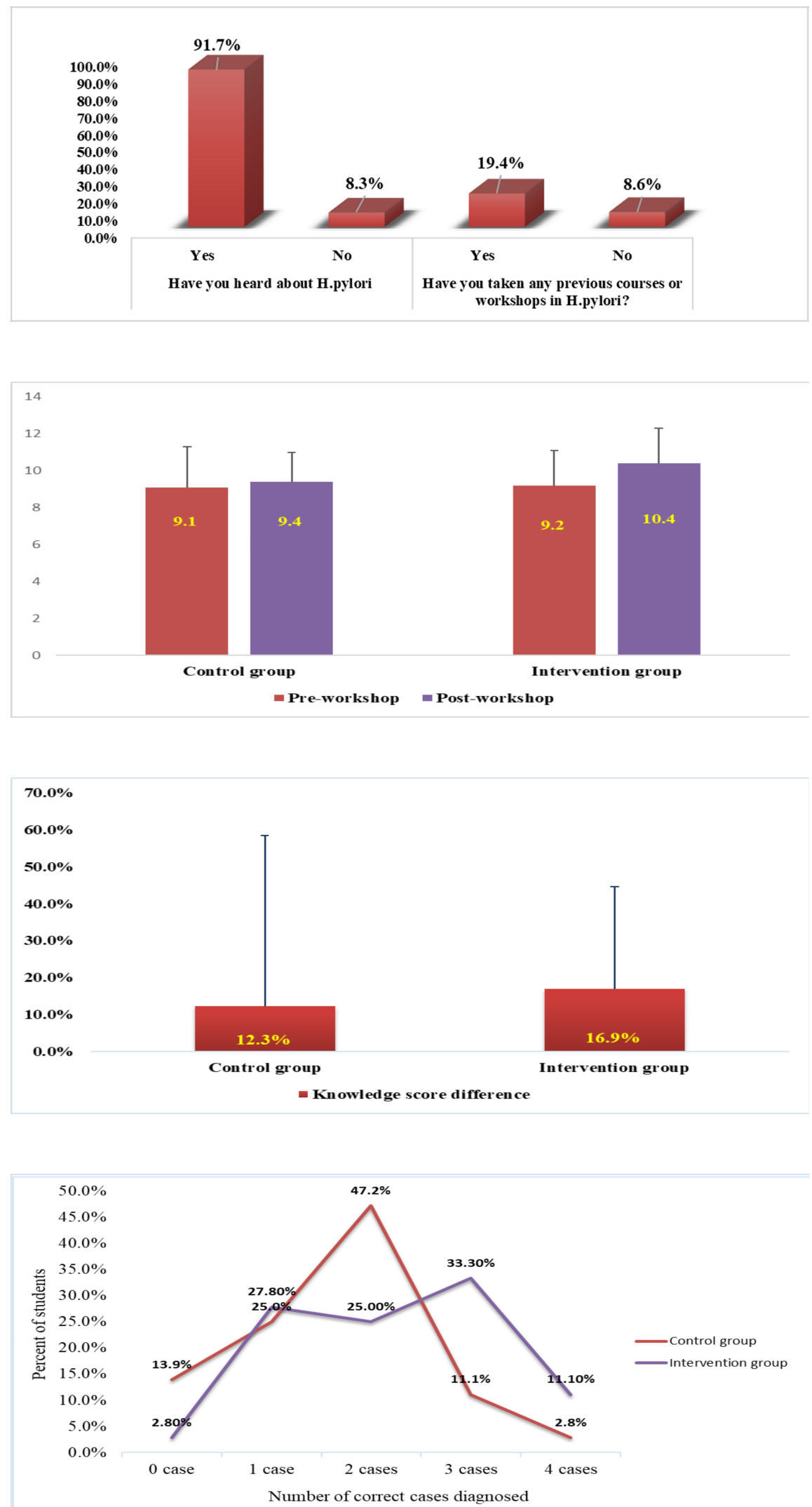


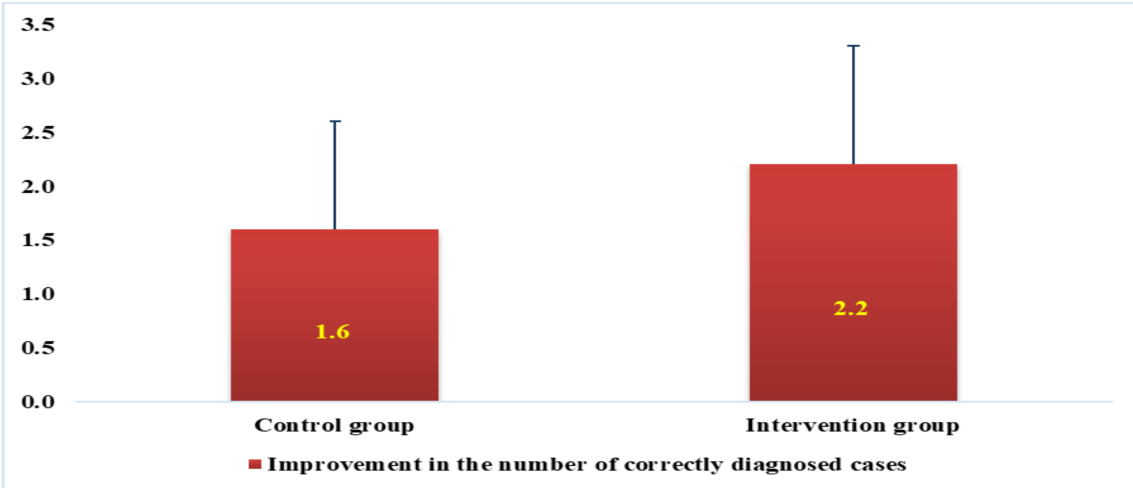

\section{Hosted file}

Tables.pdf available at https://authorea.com/users/366776/articles/486415-impact-ofeducation-workshop-on-improving-pharmacy-students-knowledge-about-helicobacter-pyloriinfection-a-randomized-controlled-study 